\title{
Technical and Economic Assessment for Optimal Sizing of Distributed Storage
}

\author{
Ismael Miranda, Nuno Silva and Helder Leite
}

\begin{abstract}
The introduction of renewable sources poses new challenges to power systems operation. Their impact on distribution networks urges the need of a more flexible grid that can ensure high reliability and power quality as well as operational efficiency.

Distributed storage systems may address those emerging challenges by covering operational needs of power, response time and energy. This paper describes a methodology for optimal sizing of distributed storage through technical and economic assessment and storage scheduling optimization.

A case study synopsis of voltage regulation and renewable energy time-shift application to $L V$ and MV networks is presented.
\end{abstract}

Index Terms-- Dispersed Generation, Distributed storage, Net Present Value, Renewable energy time-shift, Voltage regulation.

\section{INTRODUCTION}

I $\mathrm{N}$ recent years, there has been a significant growth on the power generated by renewable sources due to the global increasing environmental awareness and derived economic incentives [1]. However, the penetration of this dispersed generation (DG) brings new challenges to distribution system operation due to its intermittent nature. Thus, technical and economic issues need to be addressed in order to increase the penetration level of these energy sources and at the same time to keep high energy quality supplied to costumers [2].

Energy Storage can be a feasible technological solution that can meet these emerging challenges by compensating the operational challenges raised by the renewable sources [3]. By charging and discharging, energy storage can maintain and improve grid reliability and flexibility while integrating intermittent renewable sources, tackling eventual local voltage profile oscillations and avoiding branch overloads. Thus, an accurate interaction between energy storage and dispersed generation may not smooth renewable's benefits but even enhance them.

The purpose of this work is to optimally size distributed storage technical constraints and economic value. Voltage regulation, renewable energy time-shift are the storage applications of focus in this paper.

Ismael Miranda is with FE/UP - University of Porto- Faculty of Engineering, Porto, Portugal (e-mail: ee07240@fe.up.pt)

Nuno Silva is with EFACEC, Porto, Portugal (e-mail: nuno.silva@efacec.com)

Helder Leite is with INESC TEC/FE/UP, University of Porto - Faculty of Engineering, Porto, Portugal (e-mail: hleite@fe.up.pt)
Distributed storage state of art is reviewed in Section II. Section III describes the developed technical and economic analysis methodology, and Section IV presents two study cases and the results achieved.

\section{Distributed ENERGY STORAGE}

As the need and interest in energy storage solution rises, distributed storage technologies are being developed to commercial standards. Moreover, a variety of storage applications have been identified with the intrinsic potential benefits to each one [4]. Energy storage technologies rely on a limited range of physical or chemical processes that enable electricity to be stored [5]. These include lifting or spinning mass, compressing gas, electrons movement, chemical material manipulation and thermal storage, defining storage characteristics and the best suited application for each technology.

Distributed storage systems stand out by not having a special site requirement as they can be placed on several locations. As this work focuses on the distribution network, storage location may vary from primary to secondary substation, and even along the feeders. Moreover, most distributed energy storage systems are modular thus providing flexibility for the optimal combination of power and energy capacity levels.

According to [6], flywheel, supercapacitor and battery based storage systems are the main distributed storage technologies. They are recognized as being technologies with potential to answer the emerging challenges, and their adoption depend on the desired application.

Flywheel and supercapacitor are a high power/ low energy technology and address only power applications. Battery based systems have a multitude of technologies and chemistries and may manage both power and energy.

Although the wide array of acknowledged storage applications [4], this work emphasizes those concerning renewable integration, especially the most valuable. Therefore, voltage regulation and renewable energy time-shift are addressed in this article.

Connecting generation to distribution networks influences power flows and hence voltage profiles. Over-voltage problems arise when local DG production exceeds load and reverse power flows occur. Storage can handle over- voltage technical challenge by charging when these problems occur and, consequently, providing support to the electric grid, improving service quality and reducing DG curtailment. 
Along with this technical challenge, the best periods of the day can be selected to sell energy at higher prices rates. Managing renewable energy may improve network operation efficiency and enhance DG energy value as distributed storage can execute load and generation peak shaving.

\section{TECHNICAL \& ECONOMIC ANALYSIS OF DiSTRIBUTED STORAGE DEPLOYMENT}

This section describes the methodology developed to technically and economically assess the impact of deploying distributed storage.

The suggested analysis has a 15-year planning horizon since this is commonly used as useful life of battery systems [7]. Typical demand profiles were modelled considering two seasons throughout the year, winter (higher demand) and summer (lower demand). A typical Portuguese load curve for after diversity profiles was created for domestic, commercial and industrial customers.

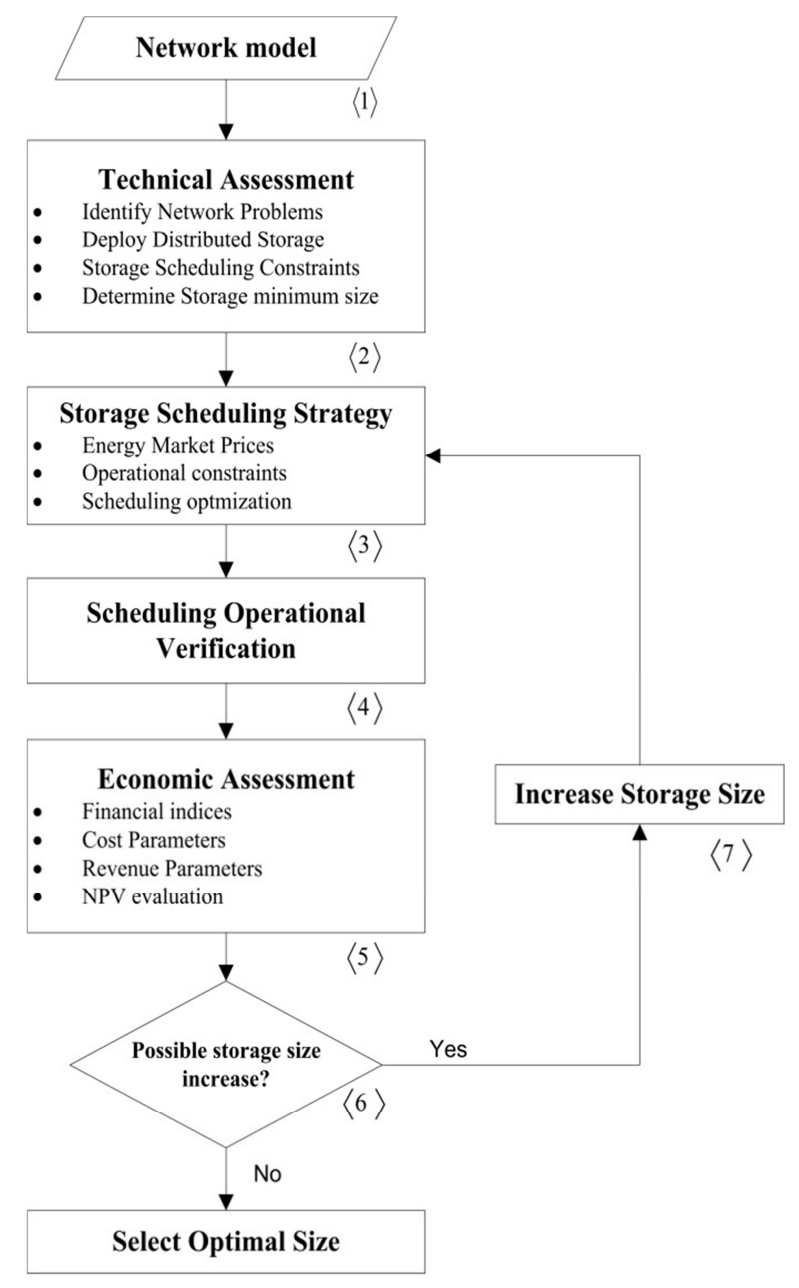

$\langle 8\rangle$

Fig.1. Optimal Sizing of Distributed Storage method

Fig.1. summarizes the developed methodology, presenting the steps needed to achieve distributed storage optimal size. The methodology begins with the acquisition of distribution network model, step $\langle 1\rangle$ in Fig.1. Beyond grid topology and technical limits, the data include hourly load and generation profiles for every load (domestic, commercial and industrial) and DG for both winter and summer.

Step $\langle 2\rangle$ uses the operational constraints set in step $\langle 1\rangle$ to identify network problems. These include bus voltage and branch thermal limits. This is attained through a series of hourly power flows. If problems are recorded, then one distributed storage system is deployed, and the appropriate location defined.

The main issue is to recognize the adequate size the storage system shall have to fulfil its purpose. Distributed storage minimum power and energy capacity needed to perform voltage regulation is highly dependent on storage location as voltage sensitivity to injected power varies at each distribution network point. Storage system is then placed at the nearest network site considered feasible, such as primary and secondary substation or along a feeder, from the most severe voltage problem as voltage sensitivity is higher near that location [8]. Along with the voltage regulation challenge, distributed storage system size may also be applied to perform renewable energy time-shift to enhance local energy management.

Minimum storage system size is achieved by solving hourly Optimal Power Flows (OPF) and managing generation costs. Setting charging and discharging prices high, the storage system only intervenes with the minimum required power and energy to perform voltage regulation and avoid congestions. Technical limits for maximum energy charging and discharging for each hourly period are calculated by a similar OPF algorithm.

The appropriate storage technology is defined considering the minimum power and energy capacity ratio as the technology must have sufficient discharge duration; the storage system location as it may require high power and/or energy densities; and the technology life-cycle depending on the minimum number of cycles that the storage system may have to perform to fulfil its purpose. The distributed storage technology will impact the minimum system size as some of them, particularly battery based, suffer from ageing phenomena. Therefore, an over dimensioning of the system size was considered based on the estimated power and energy capacity loss during the 15-year time-horizon.

Step $\langle 2\rangle$ is an optimization process to maximize the economical outcome throughout a year respecting the operational constraints, defined in step $\langle 2\rangle$. It is also assumed that charging energy has negative values and discharging positive ones. Mathematically, step $\langle 3\rangle$ is represented as follows:

$$
\max \sum_{i=1}^{N}\left(D_{i} \times R P_{i}\right)+\sum_{k=1}^{N}\left(C_{k} \times M P_{k}\right)
$$

where $\mathrm{N}$ is the number of periods in a typical day, $\mathrm{D}_{\mathrm{i}}$ is the energy discharged in Megawatt hour (MWh) in period $i, R_{i}$ is the regulation market price ( $€ / \mathrm{MWh}$ ) in period $\mathrm{i}, \mathrm{C}_{\mathrm{k}}$ is the energy charged (MWh) in period $\mathrm{k}$, and $\mathrm{MP}_{\mathrm{k}}$ is the spot market price in period $\mathrm{k}$. Hourly energy prices are based on the Iberian Energy Market (MIBEL) average prices by season 
in 2011. Charging prices are based on the standard market and discharging prices on a regulation market that depends on the storage application. If distributed storage provides an ancillary service to the network, it is assumed that it can access to the regulation markets. If not, same charging and discharging prices are considered.

Equation (1) is subject to:

$$
\begin{array}{lc}
\frac{D_{i}}{\bar{C}} \leq D_{i} \leq \overline{D_{i}} & \forall i=1 . . N \\
\overline{C_{k}} \leq C_{k} \leq \overline{C_{k}} & \forall k=1 . . N \\
\frac{\operatorname{SOC}(\%) \leq \operatorname{SOC}_{l}(\%) \leq 100 \%}{\bar{\sum} D_{i} \leq E_{\text {cap }} \times n C} & l \in[1 . . N] \\
D_{i} \times C_{k}=0 & \\
\hline
\end{array}
$$

where $\mathrm{SOC}_{1}(\%)$ is the distributed storage system state of charge in period "l", $\mathrm{E}_{\text {cap }}(\mathrm{MWh})$ is the system energy capacity and $\mathrm{nC}$ is the maximum number of full cycles that the storage technology can perform on a daily basis. In equation (2) and (3) discharging and charging limits are defined by both the network operational constraints and storage power capacity.

Equation (4) ensures that the system state of charge does not surpass the technical limit of full charge and the minimum charge state which depends on the storage technology as several of them, mainly battery systems, present a dependency of its cycle life on the SOC. Thus, the minimum charge state is set so that the storage system may perform the number of cycles required by the methodology time-span analysis. $\mathrm{SOC}_{1}$ is calculated based on equation (7).

$$
\operatorname{SOC}_{l}(\%)=\frac{-\left(\left(\sum_{k=1}^{L} C_{k}\right) \times E f f+\sum_{i=1}^{L} D_{i}\right)}{E_{c a p}}
$$

where Eff is the storage system round-trip efficiency, the amount of energy output per energy unit input, which depends on the technology. In equation (5) the maximum daily cycles is defined. If the selected technology expected life-time presents no dependence on the number of full cycles, equation (5) is discarded. Equation (6) is used to ensure that storage is not used to charge and discharge at the same time. The optimization method is solved by the interior point method.

In step $\langle 4\rangle$ in Fig.1 an hourly power flow analysis is performed to validate the scheduling strategy. Furthermore, the impact of distributed storage is assessed regarding network losses and avoided DG curtailment. It is considered that DG is curtailed by tripping of protection systems when it leads to operational limits violation.

Step $\langle 5\rangle$ main goal is to evaluate Net Present Value (NPV) as it is essential to economically assess the impact of distributed storage [7], and depends on financial indices, cost and revenue parameters. Financial indices include discount rate and inflation, which are considered to be $10 \%$ and $2 \%$ [7], respectively. Three main cost parameters are considered. The capital investment depends on both distributed storage application type and technology chosen and is considered to be paid on a 7 year period with an interest rate of $7 \%$. Maintenance costs are assumed to be a constant yearly rate of $2 \%$ of the capital investment. Energy charging cost result from step $\langle 3\rangle$.
Energy discharging, environmental and distribution network benefits define distributed storage revenues. Energy discharging revenues resulting from step $\langle 3\rangle$ of Fig.1, are considered to decay linearly each year by the amount of capacity loss when the distributed storage technology suffers from the ageing phenomena. Environmental benefits consider $\mathrm{CO}_{2}$ emission reduction. This is calculated based on the European estimated $\mathrm{CO}_{2}$ emission cost (i.e. 20€/ton- $\mathrm{CO}_{2}$ ) [8], coal and gas turbines $\mathrm{CO}_{2}$ emissions estimation by energy produced [9], and the average percentage of load fed by those sources in Portugal. Distribution network benefits include network investment cost deferral that depends on the application [7], energy not supplied by DG avoided and network losses reduction both resultant from step $\langle 4\rangle$. Investment cost deferral indicates the present worth of the storage application benefits to the distribution network and depends on the storage application considered. Although this parameter tends to vary according to the context of the electric system that it refers to, a present value of $570 €[3]$ per $\mathrm{kW}$ of distributed storage capacity is assumed, when regarding voltage regulation and renewable energy time-shift.

Step $\langle 6\rangle$ verifies if the scheduling fully utilize storage energy capacity. If not, storage optimal size is selected in step (8) considering the NPV higher value. If the grid can handle more storage capacity, then its size is increased at step $\langle 7\rangle$.

The step size depends on the minimum distributed storage size calculated, the initial power vs energy capacity ratio and the considered modularity of the storage system. Several storage technologies present discharge duration limits thus a power vs energy capacity ratio limit is defined.

\section{SynOPSIS OF THE STUdy CASES \& RESUlts}

Two study cases are presented and corresponding results of the distributed storage optimal sizing - Low voltage (LV) and Medium voltage (MV) deployment. Both study cases contemplate the application of distributed storage for voltage regulation and renewable energy time-shift. Voltage statutory limits are defined as $\pm 10 \%$ of nominal voltage.

Li-ion battery storage systems due to its fast charging, light weight and high power and energy density characteristics are selected as the storage technology in both cases and therefore a $305 € / \mathrm{kW}$ and $458 € / \mathrm{kWh}$ capital investment [11] and a $90 \%$ round-trip efficiency is considered [7].

\section{A. Low Voltage Distribution Network}

A Low voltage (LV) balanced network is modelled consisting on a 300 consumers load, $6.9 \mathrm{kVA}$ of installed capacity each. Load follows a typical Portuguese domestic profile. Photovoltaic (PV) generation was the technology adopted in this assessment which follows a Portuguese typical PV generation profile. A simplified typical LV network was modeled between loads and PV generators where a MV/LV secondary substation is supplying the network. The network was first set up with no PV generation. Scenarios of $0 \%, 25 \%$ and $50 \%$ of customers having PV microgeneration were tested. In this case, the $50 \%$ scenario is presented where 150 consumers have a $3.68 \mathrm{~kW}$ peak power PV installed each. 
Results of the technical assessment revealed a 5 hour long over-voltage problem in summer season. Consequently, one distributed storage system based on Li-ion batteries was deployed at the secondary substation LV bus bar. Although, the minimum storage size attained was of $140 \mathrm{~kW}$ and 540 $\mathrm{kWh}$, a $20 \%$ over dimensioning of both power and energy capacity is considered due to the ageing phenomena affecting this technology. It was also assumed that Li-ion batteries could perform a daily cycle (i.e. about 5500 cycles during its lifetime) with a full depth of discharge. An independent modularity of $50 \mathrm{~kW}$ and $50 \mathrm{kWh}$ is assumed in the optimal size search. Consequently, the minimum Li-ion battery power and energy capacity is $200 \mathrm{~kW}$ and $650 \mathrm{kWh}$, respectively.

The optimal storage scheduling strategy and its effect on network voltage profile at the bus further away from the secondary substation (worst case scenario) during a summer typical day is presented on Fig. 2. In order to enhance local energy management, storage system discharging limits were set so that they should not exceed local load.

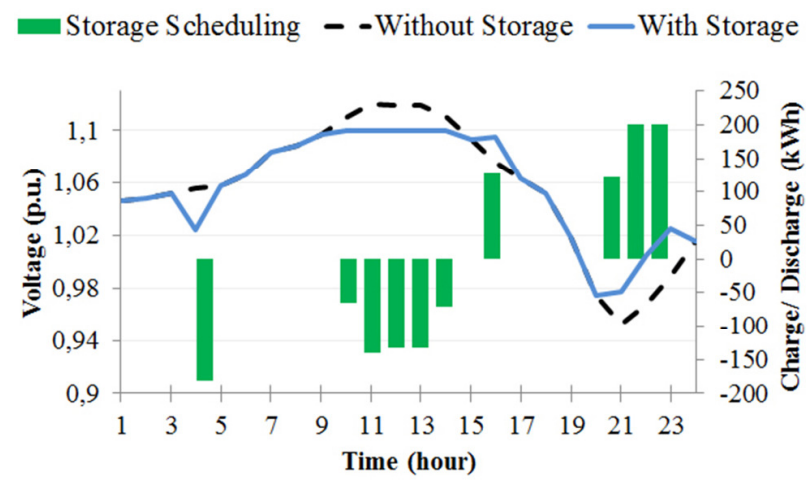

Fig.2. Effect of distributed storage on voltage profile during summer

The scheduling strategy is mainly influenced by the technical constraints as storage has to charge during overvoltage periods although that may not be the most economically suitable. Despite that fact, over voltage problems are solved and discharging on peak load demand periods improves voltage profile and enhances PV energy value demonstrating that distributed storage adequately accomplishes voltage regulation and performs PV energy time-shift.

Fig. 3 illustrates the effect of the battery system schedule on the power injected at the secondary substation during winter season. It is observable that the Li-ion storage system performed LV network peak shaving as peak demand was reduced by $36 \%$ in winter season. Moreover, the difference of the injected power at the secondary substation between low demand and high PV generation periods and peak-demand and no PV generation periods was reduced from $442 \mathrm{~kW}$ to 263 $\mathrm{kW}$. A similar effect was verified in summer season as the peak demand was shaved by $45 \%$ and the highest difference of the injected power at the secondary substation during a day was reduced by $15 \%$. The technical results reveal that the introduction of the distributed storage system improved operational efficiency and contributed to enhancing LV network energy management.

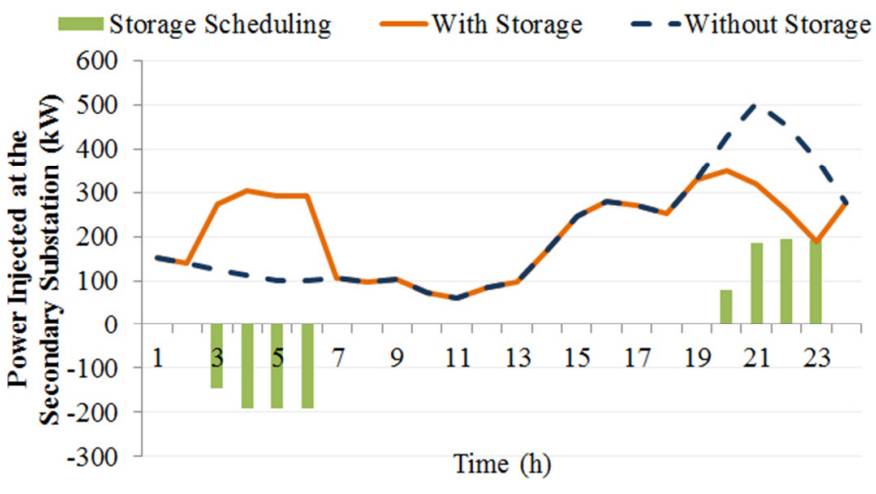

Fig.3. Effect of distributed storage on winter season power needs

Economically, results revealed that the pay-back was not achieved in the time horizon considered. In this case, a NPV of $-78.9 \mathrm{k} €$ with an Internal Rate of Return (IRR) of $2.45 \%$ was obtained. Capital investment (i.e. about $360 \mathrm{k} €$ ) exhibited a major impact on the economic outcome as the optimal storage size was the calculated technical minimum. Li-ion based distributed storage application for voltage regulation and renewable energy time-shift on LV networks would, in fact, only be economically feasible if the equivalent investment cost (IC) $(552 € / \mathrm{kWh})$ was reduced to $370 € / \mathrm{kWh}$, the effective IC that is the cost per storage energy unit (i.e. $€ / \mathrm{kWh}$ ) for the NPV to become null in the end of storage system life time. From this value, it is perceptible that Li-ion battery systems need far more development to reach commercial standards for deployment in LV distribution networks for voltage regulation and renewable energy timeshift.

\section{B. Medium Voltage Distribution Network}

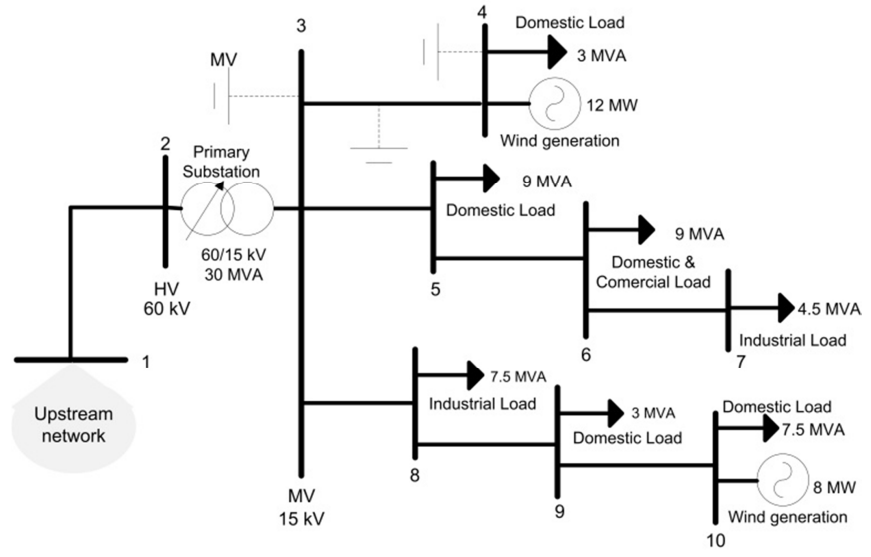

Fig.4. Study case MV distribution grid

In this study case, a simple Medium Voltage (MV) distribution network was built consisting on a primary substation supplying 3 feeders, two of which having wind generation at their end (Fig.4). Portuguese domestic, commercial and industrial typical load profiles were used, modelling its characteristic demand curve for each season of the year. Wind generation follow a Portuguese wind generation profile for each of the seasons considered (winter and summer). 
On-Load Tap Changing (OLTC) transformers were also modelled and included in these studies. The reference voltage to the tap changer was set so that no under voltage problems appear in winter at peak load periods.

Four hours of over-voltage were identified at bus 4 during low demand summer periods. In order to address over-voltage limit violation, three different locations were tested to deploy Li-ion distributed storage: at primary substation MV bus, at the middle of 3-4 branch and connected to bus 4 (see Fig.4).

Table I presents a comparison between the minimum storage capacity that resulted from the technical assessment and the minimum Li-ion storage system size that allows this storage technology to solve operational problems, considering a $20 \%$ loss of power and energy capacity in its lifetime, during the 15-year time horizon.

TABLE I

MinIMUM STORAGE SIZE AT DIFFERENT SITES

\begin{tabular}{c|c|c|c|c}
\hline \multirow{2}{*}{ Location } & \multicolumn{2}{|c|}{ Minimum Storage Size } & \multicolumn{2}{c}{$\begin{array}{c}\text { Minimum Li-ion Storage } \\
\text { Size }\end{array}$} \\
\cline { 2 - 5 } & $\begin{array}{c}\text { Power } \\
(\mathrm{MW})\end{array}$ & $\begin{array}{c}\text { Energy } \\
(\mathrm{MWh})\end{array}$ & $\begin{array}{c}\text { Power } \\
(\mathrm{MW})\end{array}$ & $\begin{array}{c}\text { Energy } \\
(\mathrm{MWh})\end{array}$ \\
\hline Primary Substation & 11 & 27 & 14 & 34 \\
\hline 3-4 Branch & 2.6 & 6 & 4 & 8 \\
\hline Bus 4 & 1.6 & 3.8 & 2 & 5 \\
\hline
\end{tabular}

The minimum storage size needed to address MV network voltage regulation increases with the distance to the bus presenting voltage issues. This relates voltage sensitivity with injected power being higher near bus 4 . However, as a higher storage size may handle more renewable energy, a more profitable economic outcome from renewable energy timeshift can be achieved.

From the results in Table II, bus 4 stands out as the selected location to deploy distributed storage with the higher return of the capital investment.

TABLE II

RESULTS OF DISTRIBUTED STORAGE OPTIMAL SIZING AT DIFFERENT SITES

\begin{tabular}{c|c|c|c|c}
\hline \multirow{2}{*}{ Location } & \multicolumn{2}{|c|}{ Optimal Size } & \multicolumn{2}{c}{ Economic Results } \\
\cline { 2 - 5 } & $\begin{array}{c}\text { Power } \\
(\mathrm{MW})\end{array}$ & $\begin{array}{c}\text { Energy } \\
(\mathrm{MWh})\end{array}$ & NPV (k€) & $\begin{array}{c}\text { IRR } \\
(\%)\end{array}$ \\
\hline Primary Substation & 14 & 34 & -9384 & -8 \\
\hline 3-4 Branch & 4 & 8 & -2055 & -6 \\
\hline Bus 4 & 3 & 5 & -1256 & -4 \\
\hline
\end{tabular}

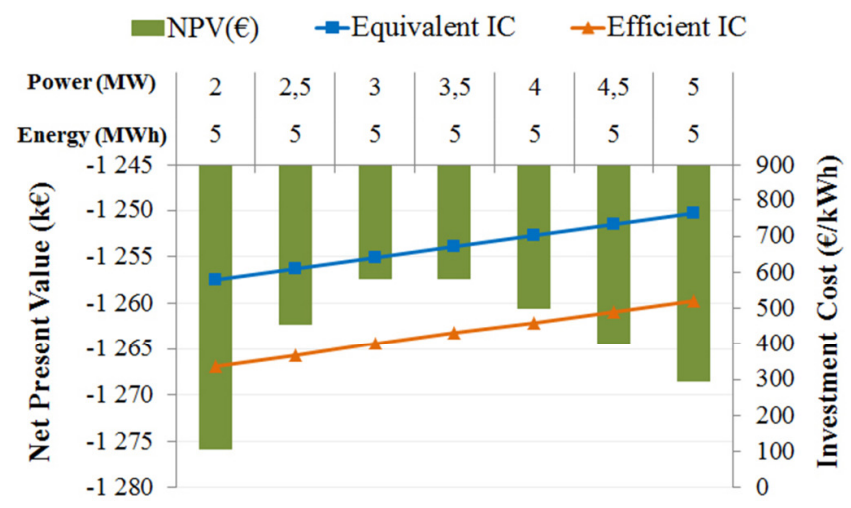

Fig.5. Distributed storage system optimal size search
Comparing Table I and Table II, it is observable that the optimal size tends to be the minimum possible technical size. Fig.5 illustrates the search for the storage system optimal power and energy capacity near the optimal size.

Distributed storage system located at bus 4 shows that a higher ratio between power and energy capacity enhances the economic outcome. This is due to the investment cost deferral that depends on power capacity and faster discharging capability as storage systems can discharge more on peak pricing periods.

In fact, investment cost deferral and storage system scheduling demonstrated to be the predominant sources of revenue of the Li-ion storage system deployed at bus 4 (see Fig. 6).

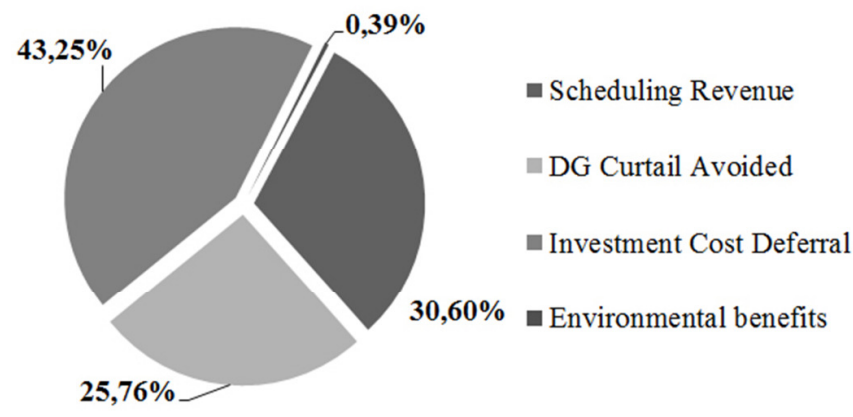

Fig.6. Predominance of the revenue parameters considered

The economic results of the optimally sized and located Liion storage system would only be profitable if the equivalent capital investment (641 €/kWh) was reduced to $281 € / \mathrm{kWh}$. Moreover, for storage systems deployment to be economically viable when locating the battery at the primary substation and on 3-4 branch, equivalent capital investment would have to be reduced from $584 € / \mathrm{kWh}$ and $610 € / \mathrm{kWh}$ to $300 € / \mathrm{kWh}$ and $282 € / \mathrm{kWh}$, respectively.

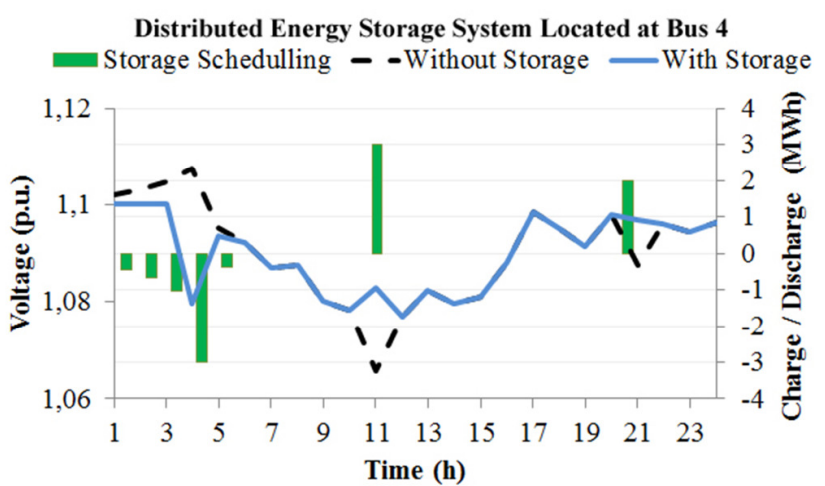

Fig.7. Effect of distributed storage on voltage profile during summer

Fig. 7 shows the optimal scheduling and voltage profile at bus 4 when the storage system is deployed there. Despite negative economic outcomes, by adequately schedule charging and discharging cycles, distributed storage successfully addressed MV network voltage regulation and wind energy time-shift avoiding DG curtailment and enhancing wind 
energy value as this energy is discharged at greater demand periods.

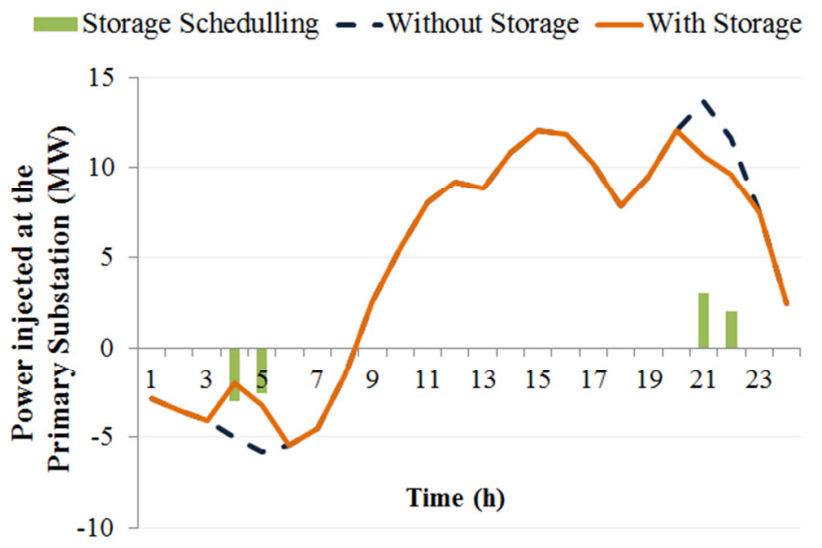

Fig.8. Effect of distributed storage on winter season power needs

Fig.8 presents the injected power at the substation with and without distributed storage deployment at bus 4. It is observable that the storage scheduling shaved peak load and generation within MV distribution network. In fact, peak demand was reduced by $12 \%$ in winter and $7 \%$ in summer season. Therefore, these systems may contribute to the local energy management enhancing local operational efficiency. In all three distributed storage sites assessed, $\mathrm{CO}_{2}$ emissions and network losses were reduced enhancing the economic evaluation. When placed at the substation's MV bus, the number of OLTC changes was also reduced mainly in winter season from 11 to 9 tap changes. Although this represents benefits to the MV network operator, it is not considered on the economic assessment. However, it is clear that distributed storage systems may extend the lifetime of other network elements such as primary substation transformers as the storage system reduces the severity network operating conditions, optimizing its performance.

\section{REMARKS}

Distributed storage presents itself as a technological solution that tackles the technical challenges to accommodate dispersed generation onto the network. As there are a multitude of technologies with diverse characteristics, storage systems may be used to perform a wide range of applications including voltage regulation, renewable energy time-shift with several technical and economic benefits. However, a careful economic evaluation must be undertaken depending on the regulatory (incentives) framework and also the macroeconomic conditions.

This work developed a methodology to systematically assess the optimal sizing and location of storage systems for a specific operational need. The work analyses the technical impact of a specific storage technology and determines the optimal capacity of such system.

The results demonstrate that distributed storage adequately handles operational constraints and also improves renewable energy value. However, in the study cases, capital investment stood up as the decisive economical parameter showing the importance of creating new regulatory and economic incentives for each application.

\section{REFERENCES}

[1] Intergovernmental Panel on Climate Change Working Group III, "Special report on renewable energy sources and climate change mitigation", Geneva, Switzerland, 2011. [Online]. Available: http://srren.ipcc-wg3.de/report/IPCC_SRREN_Full_Report.

[2] Hart, E.K.; Stoutenburg, E.D.; Jacobson, M.Z.; , "The Potential of Intermittent Renewables to Meet Electric Power Demand: Current Methods and Emerging Analytical Techniques", Proceedings of the IEEE, vol.100, no.2, pp.322-334, Feb. 2012

[3] Gyuk, I.; Mears, L.; Gotshall, H.; Kamath, H.; "EPRI-DOE Handbook of Energy Storage for Transmission and Distribution Applications", Final Report, Cap.2-5, pp.47-146, Dez. 2003, USA

[4] ESA - Electricity Storage Association, "Technology Applications", USA, 2011; [Online]. Available: http://www.electricitystorage.org/ technology/technology_applications/applications_overview

[5] Gopstein, A.M.; , "Energy Storage \& the Grid - From Characteristics to impact", Proceedings of the IEEE, vol.100, no.2, pp.311-316, Feb. 2012

[6] EPRI - Electric Power Research Institute; "Energy Storage Projects \& Demos", USA, 2011. [Online]. Available: http://disgen.epri.com/ downloads/Energy\%20Storage\%20Projects\%20Demos\%20v2011_1202 Rev\%203.xlsx.

[7] Eyer, J.; Corey, G.; "Energy Storage for the Electricity Grid: Benefits and Market Potential Assessment Guide”, Sandia Report, Feb. 2010, USA

[8] Tada, Y.; Okamoto, H.; Tanabe, R.; Kobayashi, N.; Sekine, Y.; , "Two novel screening methods to decide network configurations to maintain voltage stability using sensitivity analysis," Power Industry Computer Applications, 1999. PICA '99. Proceedings of the 21st 1999 IEEE International Conference, pp.79-85, July 1999

[9] Emissions Trading System - European Commission. http://ec.europa.eu/clima/policies/ets/index_en.htm.

[10] Lester, R.K.; Finan, A.; "Quantifying the Impact of Proposed Carbon Emission Reductions on the U.S. Energy Infrastructure", MIT-IPCEnergy Innovation Working Paper, pp. 20-25, Oct. 2009

[11] Schoenung, S.; " Energy Storage Systems Cost Update", SANDIA Laboratories Report, April 2011, USA

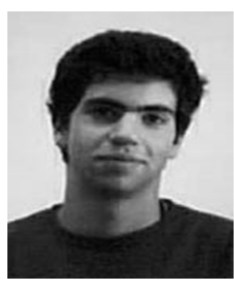

\section{BIOGRAPHIES}

Ismael Miranda (M'12) is entering a $\mathrm{PhD}$ Programme in Electrical Engineering at University of Porto Faculty of Engineering and is developing his research at EFACEC.

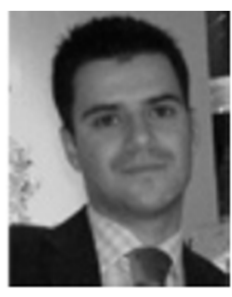

Nuno Silva (M'04) graduated from University of Porto in 2003 and finished his $\mathrm{PhD}$ in Electrical Engineering at Control and Power Group, Imperial College London in 2009. He now works at EFACEC, where he is currently the Smart Grids Architecture Lead at the Automation Business Unit. He is project manager on several smart grids initiatives and electrical mobility projects. Distributed Generation, Smart Grids, automation and optimization of power systems are his areas of activity.

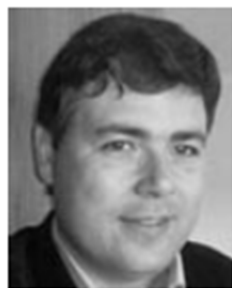

Helder Leite received his Electrical Engineering degree from University of Porto, Portugal in 2000 and the $\mathrm{PhD}$ degree in Electrical Engineering from The University of Manchester, UK, in 2004. H. Leite joined university of Porto as a Lecturer in 2005. His research interests include Distribution Generation Integration, Electric Power Systems and Power Systems Protection. 